\title{
Humanising illness: presenting health information in educational comics
}

\author{
Sarah McNicol
}

\begin{abstract}
Correspondence to Dr Sarah McNicol,

Education and Social Research Institute, Manchester

Metropolitan University, 799 Wilmslow Road, Didsbury,

Manchester, M20 2RR, UK; s.mcnicol@mmu.ac.uk
\end{abstract}

Received 21 October 2013 Revised 26 November 2013 Accepted 29 November 2013 Published Online First 7 January 2014

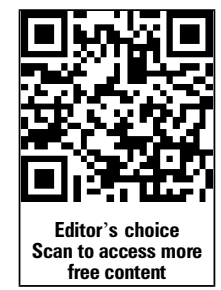

To cite: McNicol S. Med Humanit 2014;40:49-55.

\begin{abstract}
Research into the effectiveness of comic books as health education tools overwhelmingly consists of studies evaluating the information learnt as a result of reading the comic, for example using preintervention and postintervention questionnaires. In essence, these studies evaluate comics in the same way in which a patient information leaflet might be evaluated, but they fail to evaluate the narrative element of comics. Health information comics have the potential to do much more than simply convey facts about an illness; they can also support patients in dealing with the social and psychological aspects of a condition. This article discusses how some common elements of educational comics are handled in a selection of comics about diabetes, focusing on the more personal or social aspects of the condition as well as the presentation of factual information. The elements examined include: fears and anxieties; reactions of friends and family; interactions with medical professionals; selfmanagement; and prevention. In conclusion, the article argues that comics, potentially, have many advantages over patient information leaflets, particularly in the way in which they can offer 'companionship', helping patients to address fears and negative feelings. However, empirical studies are required to evaluate educational comics in a way which takes account of their potential role in supporting patients in coming to terms with their condition, as well as becoming better informed.
\end{abstract}

\section{INTRODUCTION}

As Rifas commented, "the quality of being educational can be found to some degree in any comic book". ${ }^{1}$ This is true in a general sense as social commentary is common in comics, perhaps nowhere more noticeably than the moralising frequently to be found in the storylines of superhero comics. More obviously, there is a long history of comics being used within schools and this trend appears to be growing as they are used more frequently and to teach a variety of subjects. ${ }^{2-4}$ However, comics can also have a role in informal education about a variety of issues, including health.

One can find educational comics about a wide range of illnesses. While some topics, such as AIDS and sexual health, are particularly well provided for, there are also educational comics about rarer conditions, including primary immunodeficiency, hepatitis $\mathrm{B}$ and tuberculosis, among others. ${ }^{5-7}$ Health education comics may have a number of purposes, including raising awareness (eg, of disease symptoms); preparing patients (for instance what to expect from a medical procedure); assisting with decision making (such as deciding between treatment options); promoting self-management of chronic conditions; or simply increasing understanding and acceptance of a condition. As McAllister $^{8}$ points out, comics have the potential not just to relay facts, such as risk factors for a condition, but also to deal with social issues surrounding illness.

Comics have been argued to be 'a very nonthreatening medium' as well as a 'personalising medium', ${ }^{8}$ one which 'universalises the illness experience'. 9 The fact that comics can effectively portray actions and feelings means they 'may be a very effective tool in creating empathy and compassion'. ${ }^{8}$ However, there is a danger that the effectiveness of comics as an educational tool may be limited if readers are less likely to take information provided via this medium seriously. As the format has most commonly been seen as a technique to make information accessible for low literacy patients ${ }^{10} 11$ as well as for young people or nonnative speakers, ${ }^{9}$ it is likely that the full potential of comics as a source of health information for the general population has not been fully exploited.

While educational comics are produced, primarily, for educational purposes, medical narratives or illness accounts are graphic novels and comics produced with more literary or artistic intentions. Williams argues that these narratives "offer a window into the subjective reality of other sufferers and provide companionship through a shared experience in a more immediate manner than might be gained from joining a self-help group or reading patient information leaflets". ${ }^{12} \mathrm{He}$ writes of the way in which graphic medical narratives can blur the boundaries between textbook, novel and autobiography. Similarly, educational comics, which are usually less complex than medical narratives, can be seen as constantly switching between information leaflet and storybook.

\section{COMICS AND HEALTH EDUCATION}

Research into the effectiveness of comic books as health education tools overwhelmingly consists of studies administering preintervention and postintervention questionnaires in order to determine information learnt as a result of reading the comic. In essence, these studies evaluate the 'information leaflet' component of the educational comic rather than the 'storybook' element. Reported findings focus on whether new knowledge has been acquired and sometimes whether this information is retained and whether it has resulted in changes in behaviour over a period of time. Some studies also collect data on participants' views of the comic format, whether they enjoyed reading it and so forth. ${ }^{13-15}$ 
However, in combining elements of information leaflets with sequentially illustrated narrative, health information comics have the potential to do much more than simply convey facts about an illness; they can also support patients in dealing with the social and psychological aspects of a condition. While a straightforward patient information leaflet can convey factual information, a comic can also help patients (and carers) understand much more about the fears, anxieties and expectations a patient may need to deal with. Crucially comics are able to convey this information not as generic statements, but by encouraging empathy as the reader relates to the characters in the story. Readers may, thus, gain greater insight into their own feelings and reactions. This process has been demonstrated in relation to literature more generally, for example, research involving teenagers found that while non-fiction materials on issues such as sex and drugs were useful for basic factual information, fiction was equally important because it helped in understanding the motives for, and meanings of, behaviour. Fiction allowed, in a way that non-fictional information could not, empathy with characters and learning about the potential effects of actions on health. $^{16}$

Comics, even those designed with a primarily educational purpose, also have the potential to perform a social role, the 'companionship' ${ }^{12}$ which Williams refers to, which can help to reduce feelings of isolation. They can also help the reader to view their situation from a different perspective; the patient can better appreciate the doctor's, or carer's, viewpoint and motivation, and vice versa.

An important feature of comics is the way in which they 'seem to allow more leeway in terms of meaning'; their language 'is always characterised by a plurality of messages'. ${ }^{12}$ Comics do not present a single, indisputable message, but instead rely on the reader to produce their own interpretation. The reader creates an overall meaning by relating the words and images to their own experiences. This individualises each response, meaning that comics are often characterised by the presence of multiple messages involving the co-presence and interaction of various codes. As a result, there is no single 'correct' or absolute meaning, but rather more or less equally valid alternative interpretations. As Hatfield acknowledges, the kinds of 'mixed messages' of text and images which comics send can be seen as a double-coded narrative, a device which can prove a challenge for even the most experienced of readers. ${ }^{17}$

At first sight, this 'plurality of messages' ${ }^{17}$ might seem to be a disadvantage for a resource intended to convey factual health information, but there is, of course, a great deal of uncertainty surrounding illness; two patients with the same illness can display different symptoms and respond differently to treatments. Furthermore, each patient responds to an illness as an individual, with different reactions to diagnosis and differing priorities, when undergoing treatment for example. It is precisely the ambiguity of comics which can help to capture this diversity of experience.

\section{COMICS AND DIABETES}

Diabetes is one of the health conditions most frequently featured in comics. As the range of comics available on this topic allows for comparison between different approaches and techniques used in health education comics, the remainder of this article will focus on diabetes comics.

Although comics about diabetes are not uncommon, like other educational comics, they were not always easy to discover (as described by Rifas ${ }^{1}$ in the case of AIDS comics). The comics described below were identified by a combination of internet searches and suggestions from others working in this field.

Described simply, diabetes is a condition where the amount of glucose in the blood is too high because the body cannot use it properly. This is because the pancreas does not produce any insulin, or not enough, to help glucose enter the body's cells, or the insulin that is produced does not work properly. There are two types of diabetes. Type 1 diabetes, which accounts for between $5 \%$ and $15 \%$ of people with diabetes, develops when the insulin-producing cells in the body have been destroyed and the body is unable to produce any insulin. It most usually develops during teenage years and is treated by daily insulin injections, a healthy diet and regular physical activity. Type 2 diabetes develops when the body can still make some insulin, but not enough, or when the insulin that is produced does not work properly (known as insulin resistance). Type 2 diabetes accounts for the majority of people with diabetes and is treated with a healthy diet, increased physical activity and, in some cases, medication and/or insulin. ${ }^{18}$

The comics selected for this study were chosen as examples of comics aimed at different audiences (children, teenagers and adults) and representing a variety of presentation styles and genres. The following were consulted:

- CJ has Diabetes, ${ }^{19}$ a peer-reviewed comic aimed at a preteen audience.

- What's Up with Ella? Medikidz Explain Type 1 Diabetes ${ }^{20}$ one of the Medikidz series of peer-reviewed superhero comic books that aim to help children and young people learn about medical conditions ${ }^{\mathrm{i}}$

- My New Shadow, ${ }^{21}$ produced by a non-profit health information charity and aimed at teenage girls

- The Mysterious Symptoms, ${ }^{22}$ produced by the same health information charity, but for adults with type 2 diabetes

- Diabetes is After Your Dick!, ${ }^{23}$ a humorous comic aimed at men by Cathy Leamy.

The first four titles are targeted towards people recently diagnosed with diabetes, while Diabetes is After Your Dick! is aimed at a more general audience with its main message being diabetes prevention. CJ has Diabetes, The Mysterious Symptoms and My New Shadow follow a character from the appearance of symptoms of diabetes, through diagnosis and the subsequent impact of diabetes on their everyday life. While some titles, such as CJ has Diabetes, are straightforward, suggesting that the main aim is to impart information, others indicate a stronger narrative element, such as a mystery to be solved. The most humorous comic studied, Diabetes is After Your Dick!, clearly indicates in the title that it will have an irreverent approach.

The following discussion compares how some common elements of educational comics are handled in the selection of comics chosen for this study, focusing on the more personal or social aspects of the condition as well as the presentation of factual information. The elements examined are: explanations of diabetes; symptoms and diagnosis; fears and anxieties; reactions of friends and family; interactions with medical professionals; self-management; and prevention. Not every comic is not considered with regard to every element, rather examples are purposively selected to illustrate the differing approaches which can be taken.

${ }^{\mathrm{i}}$ This was updated as, What's Up with Ashleigh: Medikidz Explain Type 1 Diabetes in 2012. 


\section{Symptoms and diagnosis}

The Mysterious Symptoms has the most direct approach to discussing the symptoms of diabetes; Alicia, the patient, complains of thirst and tiredness on the front cover. CJ has Diabetes uses a slightly more sophisticated technique, presenting the common symptoms of diabetes as a montage suggesting the ways in which CJ is affected during the course of a day. This helps to increase the reader's understanding of the various ways in which symptoms can be presented, as well as creating sympathy for the character as it is clear that many aspects of his life are being affected.

What's Up with Ella? takes a very different, and more entertaining, approach to explaining the symptoms of diabetes and showing how a doctor would determine whether someone had diabetes. The explanation takes the form of a humorous and surreal game show format with the Medikidz superheroes answering questions while being interrupted by personified glucose.

Comics offer an opportunity to show, very graphically, the ways in which a patient may react to a diagnosis. All the comics studied reassure the reader that negative feelings are normal on receiving a diagnosis. My New Shadow, has the most ominous title, and it has the most initially pessimistic view of diabetes, "Little did I know that my wonderful, crazy, fun-filled life was about to turn ugly!”. When Rachel receives her diagnosis, the image is dark and Rachel is shown with a scared expression and hunched posture, visibly isolated from her mother and the doctor by her position in the panel. Like Rachel, CJ in CJ has Diabetes is scared and longs to go back to a time before he had diabetes. In a similarly dark image which heightens the sense of isolation and fear, he says, "I wished I could go back in time and make this not happen to me". Comics therefore show characters experiencing many fears and anxieties immediately after being diagnosed, a feeling newly diagnosed patients are likely to be able to empathise with, but they also suggest ways in which these concerns can be overcome, as described below.

\section{Fears and anxieties}

A range of fears and anxieties are portrayed within the comics studied, including fear of injections, concerns about hypoglycaemia or hyperglycaemia; fear of forgetting how to manage diabetes; worries about future complications; and alarm at the impact diabetes might have on everyday life.

In $C J$ has Diabetes, CJ's immediate reaction is extreme and dramatic, "I thought having diabetes meant I was going to die because I ate too much candy". His fear at having to spend a night in hospital is clear from the blue-purple tinged images at this point and his nervous expression. Concern is heightened as CJ's mother is also shown to be alarmed and tearful, and his father races to the hospital.

Rachel too admits to feeling scared in My New Shadow as, "everything felt like it was moving in slow motion"; the alienation is clear as there is a close-up of Rachel's face as a disembodied voice calls her name. The speech bubbles and illustrations emphasise the disjunction between Rachel's thoughts and words as she says, "Yes, doctor. No, doctor. I understand, doctor" while looking clearly sceptical. She is evidently not digesting the information immediately and it is only later that the realisation sinks in that the condition means she will have to inject herself regularly for the rest of her life, as her wide, scared eyes at this point indicate.

The fear of injections and blood tests as a routine aspect of diabetes is common in the comics studied. Importantly, in $M y$
New Shadow, reassurance is offered by the patient, rather than the medical professionals; Rachel gains strength and confidence from realising that she is able to inject herself, "I guess finding out I could successfully give myself a shot calmed me down". In this image, Rachel looks strong and in control in the centre of the frame, as she administers the injection; the medical professionals are consigned to the background of the image. Similarly, in What's Up with Ella, one of the Medikidz superheroes expresses a concern a child may have: "Blood test? Is that going to hurt!?", but again it is Ella herself who dismisses this concern, reassuring him, "I've had that test. You can hardly feel it!". These comics therefore aim to reassure children and young people that this will not be as painful or scary as they may imagine.

A fear of not being able to manage diabetes correctly is another concern. In The Mysterious Symptoms, Alicia is concerned she will not remember what the doctor has said during the consultation; she is reassured by the nurse that this is normal and she will come to understand more in time, "It takes time to learn all the things you need to know". When explaining that the amount of insulin needs to neither too low nor too high, the Medikidz in What's up with Ella? make use of humour to reassure Ella that her doctor or nurse will help to find the amount that is 'just right', alongside an illustration of three insulin syringes on beds, making reference to the 'The Three Bears' fairy tale: Papa Insulin, Mama Insulin and the dose which is 'just right'.

Possible complications which may arise from diabetes are mentioned in the comics, but are not a central theme, suggesting they are considered unlikely to be an immediate concern to the intended audience of newly diagnosed patients. However, the comic focusing on diabetes prevention, Diabetes is After Your Dick, makes ingenious use of the complications which can arise to put across its message. It provides a humorous take on possible male reactions to diabetes. Men are shown dismissing the serious health problems which can result if diabetes is untreated such as stroke, eye problems and losing a foot, "Fine, I'll be a peg leg pirate every Hallowe'en". However, the response to the news that diabetes may lead to erectile dysfunction, is very different, "Oh my God! How?!”.

\section{Explaining diabetes}

The need for information to help a patient to more thoroughly understand diabetes is a recurring theme; for example What's Up with Ella? has highly detailed descriptions of what normally happens inside the body and how this differs for someone with diabetes. This is illustrated in a style which is highly visual, through the personification of glucose and insulin and the use of metaphors such as an insulin factory staffed by $\beta$ cells which is attacked by an army of white blood cells, and cells as nightclubs which only admit paired couples of insulin and glucose (figure 1). Diabetes is After Your Dick! also makes use of a visual metaphor to explain diabetes; insulin is 'the delivery guy' and cells are 'his customers' who normally are keen to receive a package of glucose. In type 1 diabetes, there is no delivery guy (no insulin), while in type 2, he tries to deliver parcels, but the customers refuse to let him in, so the glucose is left blocking the road (figure 2).

In contrast, in The Mysterious Symptoms, the explanation of diabetes is much more prosaic and is delivered as a monologue by the doctor extending over a number of pages and accompanied by some very basic medical textbook style illustrations (figure 3). 
Figure 1 What's up with Ella? Medikidz explain type 1 diabetes (Illustration courtesy of Medikidz).

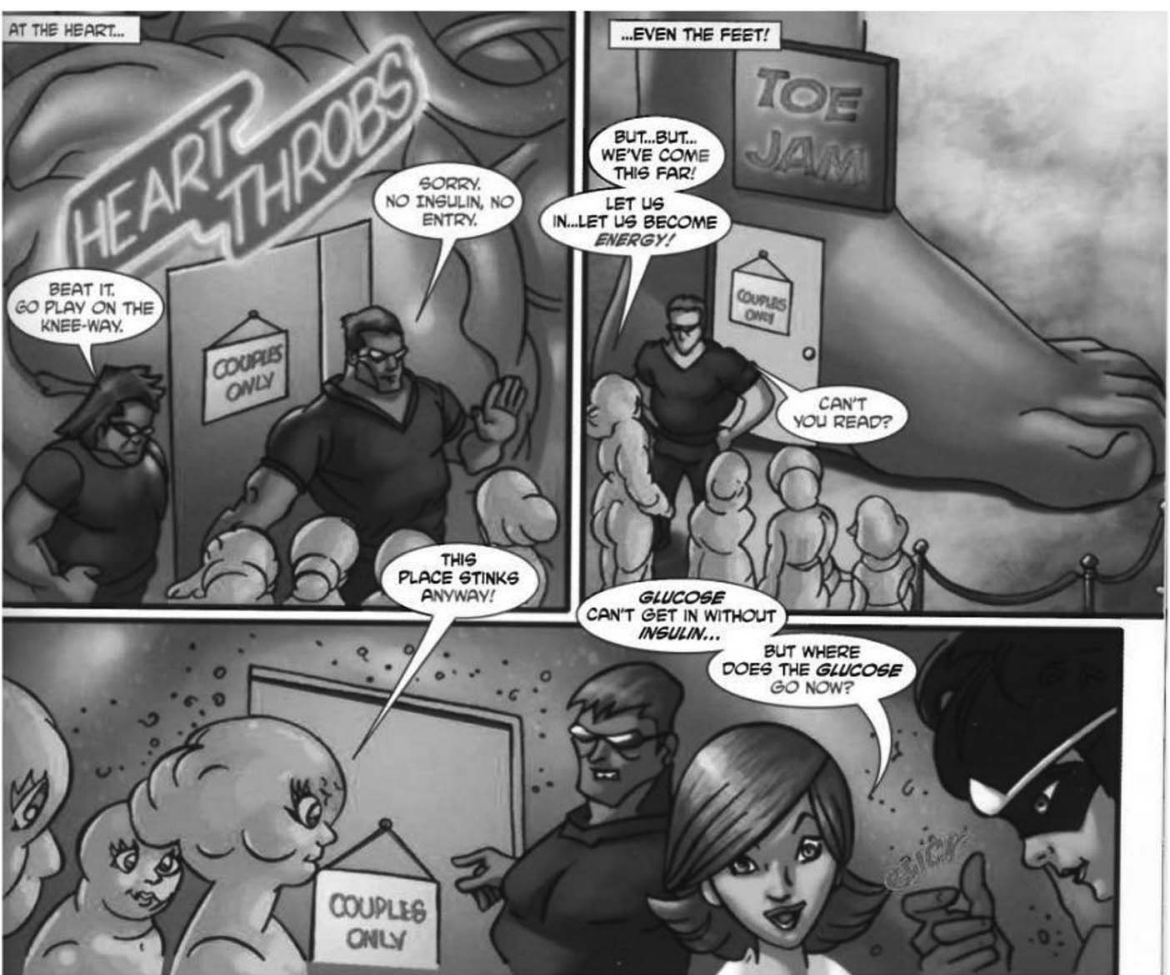

Reactions of friends, family and others

Crucially, the comics studied do not simply focus on the patient, but also develop other characters, allowing the reader to view the situation from the perspective of friends and family too. The potential audience for a comic is a factor in determining

\section{SO WHAT'S DIABETES? YOU MIGUT WAVE} HEARS THAT THERE'S TWO KINOS.

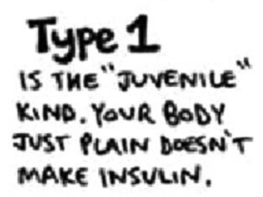

NO DELIVERY GUY!
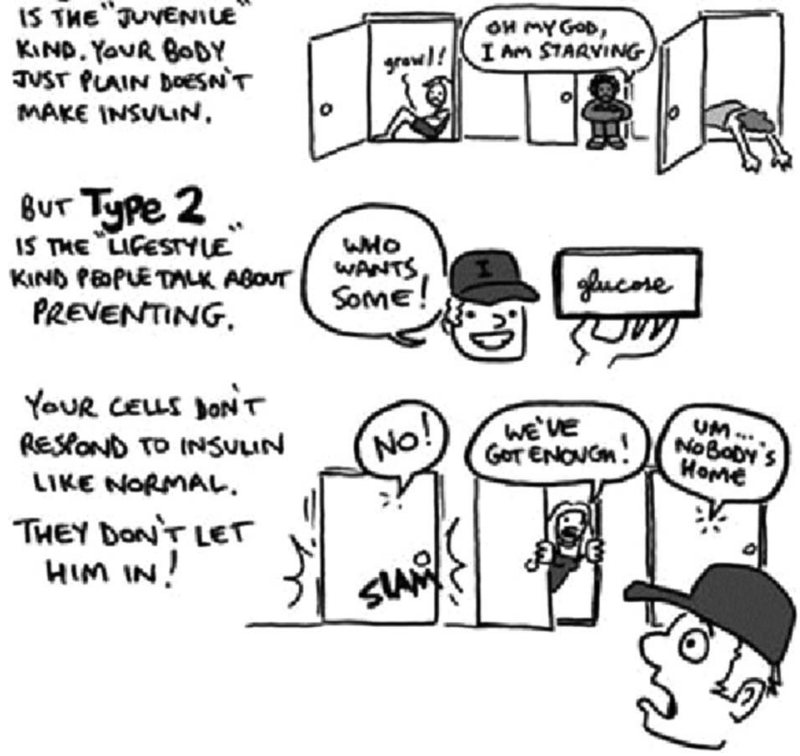

Figure 2 Diabetes is after your Dick! (Illustration courtesy of Cathy Leamy). the depiction of the reactions of friends, family and society more widely. As well as differences due to the age group the comic is aimed at, cultural differences are apparent. In common with other diabetic comics aimed at the Latino community, ${ }^{24}$ the involvement and reactions of family is a strong feature of The Mysterious Symptoms. It is Alicia's daughter who suggests she should visit a doctor and one of Alicia's first concerns is whether she will still be able to take care of her family. Her family are closely involved in the management of her diabetes, reminding her to exercise and check her blood sugar.

$\mathrm{CJ}$ has Diabetes also emphasises the role of family. As CJ is a child, this is not unexpected; it is CJ's mother who takes him to see the doctor. However, CJ becomes aware his family are treating him differently and he clearly wants greater independence; he struggles to accept his family's reactions, "my family still fussed over me and said they were 'sorry'. I hated that part". The conflict between a caring family and a desire for greater independence as a young adult is an important aspect of comics aimed at this age group. Like CJ, Rachel in My New Shadow is at first annoyed at her family's response. In a telling image, the reader looks down on Rachel, as if from the position of a CCTV camera, as she is surrounded by portraits which appear to be scrutinising her. The explanation, "I felt like everyone was watching me", is almost superfluous. However, she quickly comes to realise the importance of family support, "It sure felt good to know that Mom was there".

Reactions of those beyond a patient's immediately family also feature. In My New Shadow, Rachel is concerned about how her friends will react, "Would they freak out if they saw me checking my blood sugar?'. Although her friends are portrayed as caring, their ignorance of diabetes makes Rachel uncomfortable, as one asks "But can...can people catch it?". Nevertheless, the eventual acceptance of her classmates helps her to come to terms with her condition. Furthermore, the comic shows that even negative reactions can be used in a positive way as it the 
Figure 3 The Mysterious Symptoms (Illustration courtesy of Learning About Diabetes, http://www. learningaboutdiabetes.org).
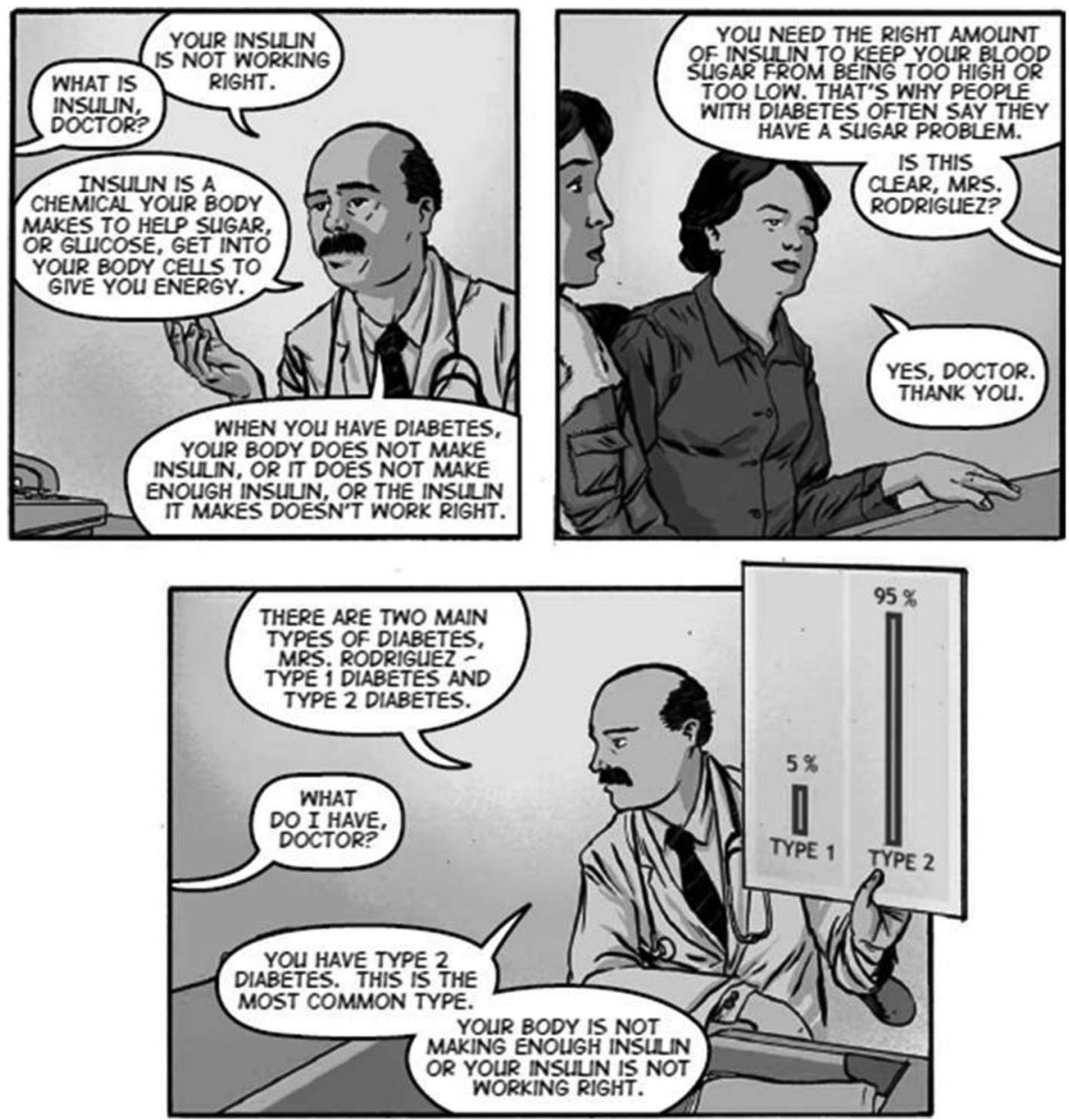

unsympathetic reaction of the school bully which galvanises Rachel and makes her regain her confidence to stand up for herself.

Similarly in CJ has Diabetes, CJ is concerned about how his friends will react. On his first day back at school, a small, apprehensive CJ enters through large foreboding doors. But there is a reassuring message as his friends react more positively than he had hoped, "It made me feel good that they were curious, but not scared". In this frame, CJ is foregrounded in vibrant colours, demonstrating his growing confidence.

The importance of discovering other people who can relate to experience of life with diabetes is stressed in several comics. In My New Shadow, Rachel feels more comfortable about having diabetes once she meets other young people with the same condition, "There are other kids like me in school. I'm not alone!". In CJ has Diabetes, CJ becomes more positive when he discovers that one of his nurses has diabetes, "I like knowing she can really understand what I'm going through". The storytelling nature of comics also allows role models to be introduced as characters. CJ is shocked to discover that his confident, athletic-looking sports coach also has diabetes, but this knowledge makes him more determined to succeed, "If he could have diabetes and still be that fast, I knew I could too".

\section{Interactions with medical professionals}

As well as learning to deal with the reactions of friends, family and other people, diabetes patients also need to navigate their way through interactions with members of the medical and healthcare profession.
In My New Shadow, The Mysterious Symptoms and CJ has Diabetes, medical staff are kind and helpful, but generally onedimensional characters; their role is to impart information and their characters are not well developed. Reinforcing the traditional patriarchal structure associated with medicine, in all three cases, the male doctor is supported by a chorus of female nurses, dieticians and educators performing auxiliary roles. Only Diabetes is After Your Dick! reacts against this tradition by presenting a female doctor.

In The Mysterious Symptoms, medical professionals are portrayed as highly knowledgeable and estimable. The role of the doctor and nurse in the story is to present a constant flow of factual information, only interrupted when Alicia seeks clarification, or thanks them (figure 3). In CJ has Diabetes, the doctor is again presented as an unassailable expert, ready with the answers, "Dr Mitchell knew right away...". Similarly, Ella is reassured by the Medikidz, "There will always be lots of doctors and nurses around to support you". The medical profession is portrayed as admirable, 'clever doctors'.

However, while in The Mysterious Symptoms, Alicia is portrayed as submissive and compliant in her interactions with the doctor, in What's Up With Ella?, Ella displays a more spirited reaction at times: "High! Low! Too much! Too little! You people are driving me crazy!" . The doctor-patient relationship is even more strained in My New Shadow as Rachel has a much more cynical attitude towards the medical professionals, mocking them as a 'parade of happy helpers'.

In Diabetes is After Your Dick!, the role of medical professionals features much less strongly. Most of the information is delivered by the narrator; a doctor only features in the very last frame, when 
a much less subservient doctor-patient relationship is suggested, "Got issues? Tell your doctor! Man, that's what you're paying them for!", "Here's my list of what I want to fix!". Crucially, the doctor is shown as being receptive to this approach.

\section{Self-management}

The importance of self-management to control diabetes is emphasised in the comics studied and the message of patient responsibility features strongly. Following a section outlining some of the possible serious consequences of diabetes, such as stroke and kidney problems, the Medikidz describe what actions can be taken to prevent these problems developing. They emphasise that self-management is 'really important'. This is not especially reassuring, but does make Ella feel grown up, 'Make the responsibility yours'. Therefore, while the importance of doctors and patients working together is stressed; patient responsibility is the key. In The Mysterious Symptoms, the doctor says, "We will work together, Mrs Rodriguez, to develop a plan that will help you control your diabetes" but "controlling your blood sugar levels day-by-day will be up to you".

In Diabetes is After Your Dick!, self-management is likened to the self-discipline required by a martial arts expert, as the patient is portrayed as, 'the Bruce Lee of blood sugar!', implying that, with sufficient discipline, diabetes can be managed effectively. However, in CJ has Diabetes, a more realistic approach is presented, showing that things can go wrong, not matter how much care is taken. When CJ has a growth spurt, he learns that 'being in control' should be the aim, rather than 'being perfect'.

\section{Prevention}

The storytelling techniques of comics allow the author to present the most negative aspects of diabetes, but then to immediately combat this by focusing on prevention and management. For example, in Diabetes is After Your Dick!, following an explanation of how diabetes can cause erectile dysfunction, the male characters adopt a boxing stance, indicating they are ready to take action, 'Let's fight this! What do we do?'. Diabetes is After Your Dick! makes good use of the personal nature of comics, showing the male characters doing specific activities such as marching while watching television. Others capitalise less on the comics format; in The Mysterious Symptoms, prevention advice is presented in a more static format by the healthcare professions and using flip chart-type displays.

In addition to differences in presentation, variation is apparent in the message of the comics depending on the intended readership. In comics aimed at Latino audiences, such as The Mysterious Symptoms, the notion of fate is common, the belief that nothing can be done to prevent illness; it must simply be accepted. This belief is discussed by the characters, but it is rejected forcefully, "Rico's mom has diabetes and she says it's fate. There is nothing anyone can do about it", "That's not true. There's a lot that I can do".

\section{DISCUSSION}

The comics discussed in this paper represent very different ways of communicating health information. While, to assist comparison, the comics chosen all deal with diabetes, many of the themes and issues discussed could equally apply to other illnesses and health issues. Of course, the potential advantages of educational comics suggested in this article are based on a theoretical study of the text alone; empirical studies with patients, and other readers, are needed to validate, or refute, the assertions made.

Comics, potentially, have many advantages over patient information leaflets by offering 'companionship'. ${ }^{12}$ While there may be no easy answer to some concerns, portraying characters in a similar situation to them with whom patients can empathise may reduce isolation. Each reader forms their own interpretation and makes their own meanings from the comic by reflecting on the ways in which the experiences of the characters intersect with their own.

Anxiety often arises from uncertainty, for example when someone who is newly diagnosed considers how their life may be affected. As the comics studied show, it is not just the obvious changes such as blood sugar testing, but also more subtle changes like the reactions of friends and family which can be shown effectively through the story-telling approach of comics. Comics are also able to capitalise on the highly personalised nature of the medium; rather than conveying general information which could be provided in an information leaflet, they are able to show characters in the stories performing actions, for example, taking exercise. Comics can also be an appropriate format to raise, and dismiss, erroneous beliefs as one character can express such a belief, which is disputed by others in whom the reader places greater trust, such as the patient themselves or a medical professional.

However, while such arguments can be made in favour of providing health information through the use of comics, the design of some of the health education comics currently available does not appear to be taking full advantage of the potential of the comic book format. Information may be presented in a static, disengaged way, rather than making use of powerful literacy and visual devices such as metaphor and personification. The visual component of a comic can make the text more memorable if the two elements work together interdependently. While the text may contain all the factual information necessary, the images reinforce this understanding and help commit it to memory. This capitalises on one of the strengths of comics, the interplay of text and image.

Humour is used effectively in some comics to capture the reader's attention and make the health message more memorable. There are also examples of slightly surreal components of comics which can be effective in grabbing the reader's attention by presenting information in an alternative, memorable way. Of course, not all comics need be humorous, but as educational comics rarely have a compelling storyline to draw the reader in, the use of humour would seem to be one of the best ways to gain the participation of the reader as the author's 'silent accomplice', ${ }^{25}$ an act which requires more active engagement than that employed when reading a more straightforward text such as an information leaflet.

\section{CONCLUSION}

While it is important to evaluate the factual comprehension of health education comics, it is also essential to consider how reading a comic may impact on a patient's mental state, not merely whether they have retained pertinent facts. Examples may include whether they feel more positive about their condition and life in general; whether the story has led them to rethink their relationships with friends and family or medical professionals; whether any of their fears have been allayed; or whether their attitude towards self-management or prevention has altered. Only when studies are undertaken to evaluate educational comics in this way will it be possible to say whether the various styles of educational comics available actually possess the types of potential benefits for patients discussed in this article.

Competing interests None.

Provenance and peer review Not commissioned; externally peer reviewed. 


\section{REFERENCES}

1 Rifas L. AIDS Educational Comics. Ref Serv Rev 1991;19(2):81-7.

2 Aiken K. Superhero History: Using Comic Books to Teach U.S. History. OAH Mag Hist 2010;24(2):41-7.

3 Gerde VW, Foster RS. X-Men ethics: Using comic books to teach business ethics. J Bus Ethics 2007;77:245-58.

4 Hall KJ, Lucal B. Tapping into Parallel Universes: Using Superhero Comic Books in Sociology Courses. Teach Sociol 1999;27:60-6.

5 Immune Deficiency Foundation. IDF Presents: Battle of the bands. 2013. http:/l primaryimmune.org/wp-content/uploads/2013/03/IDF-Comic-Book-Battle-of-theBands.pdf (accessed 11 Aug 2013).

6 BIO Comics. Attack of the Hep B virus! Captain Bio. Tim Peters and Company, Inc, 1997. http://www.timpetersandcompany.com/assets/bio_comics/HepB_Adol_comic LR.pdf (accessed 11 Aug 2013).

7 The New York City Department and Health and Mental Hygiene. Friends forever: A triumph over TB. 2006. http://www.nyc.gov/html/doh/downloads/pdf/tb/ tb-patient-comicbook.pdf (accessed 11 Aug 2013).

8 McAllister MP. Comic books and AIDS. J Popular Cult 1992;26(2):1-24.

9 Green MJ, Myers KR. 2010. Graphic medicine: use of comics in medical education and patient care. BMJ 2010;340:c863.

10 Zielinski C. Publishing for the grass roots: a comic book on immunization. World Health Forum 1986;7(3):273-7.

11 Toroyan T, Reddy P. Participation of South African Youth in the design and development of AIDS photo-comics. Int Q Community Health Educ 1997:17:131-46

12 Williams ICM. Graphical Medicine: Comics as Medical Narrative. Med Humanit 2010;38:21-7.
13 el-Setouhy MA, Francisco RF. Stigma reduction and improved knowledge and attitudes towards filariasis using a comic book for children. J Egypt Soc Parasitol 2003;33(1):55-65.

14 Kovacs F, Oliver-Frontera M, Plana M, et al. Improving schoolchildren's knowledge of methods for the prevention and management of low back pain: a cluster randomized controlled trial. Spine 2011;36(8):E505-12.

15 Milleliri J, Krentel A, Rey JL. Sensitisation about condom use in Gabon (1999): evaluation of the impact of a comic book. Sante 2003;13(4):253-64.

16 McNicol S. Teenagers, reading and censorship: Teenagers' views on censorship in libraries. 2006. http://www.ebase.bcu.ac.uk/docs/censorship-teenage-focus-groupsreport.pdf (accessed 11 Aug 2013).

17 Hatfield C. Alternative comics: An emerging literature. Jackson, MS: University of Mississippi, 2005.

18 Diabetes UK. Guide to Diabetes. 2012. http://www.diabetes.org.uk/Guide-todiabetes/ (accessed 11 Aug 2013)

19 Olson J. CJ has Diabetes. Atlanta, GA: Pritchett \& Hull Associates, 2005.

20 Chilman-Blair K, Taddeo J. What's up with Ella? Medikidz explain type 1 diabetes. London: Medikidz Ltd, 2009.

21 Learning About Diabetes. My New Shadow 2012. http://www.learningaboutdiabetes. org/comic/MyNewShadow_fullcomic.pdf (accessed 11 Aug 2013).

22 Learning About Diabetes. The Mysterious Symptoms. 2007. http://www. learningaboutdiabetes.org/downloads/MysteriousSignsEN.pdf (accessed 11 Aug 2013).

23 Leamy C. Diabetes is after your Dick! 2012. http://www.metrokitty.com/comics/ webcomics/diabdick/ (accessed 11 Aug 2013).

24 U.S. Department of Health and Human Services. Watch Out for Your Vision! Bethesda, MD: National Eye Health Education Program, 2009.

25 McCloud S. Understanding comics: the invisible art. New York: Harper Collins, 1994. 